\title{
La Economía Global en tiempo de crisis del covid-19
}

\section{The Global Economy in Time of Covid-19 Crisis}

\author{
ZUÑIGA, Luis M. ${ }^{1}$ \\ RESTREPO, Luis $C^{2}$ \\ OSORIO, Roberto $\mathrm{C}^{3}$ \\ BUENDÍA, Juan C. ${ }^{4}$ \\ MUÑOZ, Helmer ${ }^{5}$
}

\begin{abstract}
Resumen
La pandemia actual desencadenada por el SARS-CoV-2/ COVID-19 ha puesto a prueba la capacidad de respuesta de los diferentes sistemas de salud en el mundo e incluso a la economía. Es de saber que las pandemias han acompañado al ser humano desde sus orígenes; sin embargo, mucha incertidumbre surge a partir de preguntas acerca de los diferentes escenarios que pueden presentarse durante el curso de la enfermedad o posterior a ella. El objetivo de este articulo parte de la necesidad de comprender como se ha afectado la globalización desde la perspectiva económica, como resultado se llega a que reconociendo el hecho de que el mundo ha cambiado mucho desde que se declaró la enfermedad epidémica, los gobiernos se han visto en la obligación de recurrir a las medidas de confinamiento como una opción para contrarrestar la propagación del covid-19, no obstante la economía mundial se ha visto afectada porque las personas han dejado de consumir productos y servicios de ciertos sectores, de igual manera la reapertura económica como lo mencionan distintos autores puede dar un respiro a la economía a largo plazo, pero aun así entre la humanidad esta infundido el miedo por lo que habrá cierta incertidumbre.
\end{abstract}

Palabras claves: economía, globalización, covid 19, confinamiento, incertidumbre

\begin{abstract}
The current pandemic triggered by SARS-CoV-2/ COVID-19 has tested the responsiveness of different health systems around the world and even the economy. It is to be known that pandemics have accompanied humans since their origins; however, a lot of uncertainty arises from questions about the different scenarios that may arise during or after the course of the disease. The objective of this article is based on the need to understand how globalization has been affected from an economic perspective, as a result it is recognized that recognizing the fact that the world has changed a lot since the epidemic disease was declared, governments have been forced to resort to confinement measures as an option to counteract the spread of covid-19, yet the world economy has been affected because people have stopped consuming products and services from certain sectors, just as economic reopening as mentioned by different authors can give a long-term respite to the economy.

Keywords: economy, globalization, covid 19, confinement, uncertainty
\end{abstract}

\footnotetext{
${ }^{1}$ Docente Investigador, Programa Administración de Empresas, Corporación Unificada Nacional de Educación Superior CUN, Administrador de Empresas, MsC en Administración y Planificación Educativa. Luis_zuniga@cun.edu.co

2 Docente Investigador, Programa Administración de servicios de salud, Corporación Unificada Nacional de Educación Superior CUN, Abogado, MsC en Administración de los RRHH, Candidato a Doctor en Ciencias Políticas. luis_restrepoj@cun.edu.co.

${ }^{3}$ Docente Investigador, Programa Administración de Empresas, Universidad Cooperativa de Colombia, Ingeniero Industrial, MsC en Dirección y

Administración de Empresas. roberto.osoriom@campusucc.edu.co

${ }^{4}$ Docente Investigador, Programa Administración de Empresas, Corporación Unificada Nacional de Educación Superior CUN, Administrador de Empresas, MsC en Administración. juan_buendia@cun.edu.co

${ }^{5}$ Docente Investigador. Líder Grupo de Investigación AXON. Ingeniero de Sistemas. MsC en Ingeniería de Control Industrial. PhD en Gerencia. Postdoctor en Procesos Sintagmáticos de la Ciencia y la Investigación. helmer_munoz@cun.edu.co
} 


\section{Introducción}

Este trabajo parte de la necesidad de poder comprender la dinámicas globales y como en el marco de la pandemia de covid-19 las naciones y las organizaciones han hecho frente a esta problemática, se parte de la premisa de que muchos países desde sus débiles perspectivas del comercio exterior como lo son las naciones de América Latina y el Caribe hacen frente con sus mayores esfuerzos en no caer en una recesión mientras luchan por mantener sus centros hospitalarios trabajando y de igual manera intentando recuperar su economía desde la incertidumbre.

Si bien las políticas de diferentes gobiernos para lograr contener la expansión del covid-19 con la aplicación de cuarentenas y cierres temporales son necesarias, de igual forma han ocasionan la reducción del comercio internacional, presentándose interrupciones en las cadenas de suministro. Esta crisis se presenta en un ámbito en el que ya se venían observando fricciones comerciales, bajo crecimiento económico y una deuda que cada vez más se acumulaba. En el siguiente trabajo se hace un estudio a través de una revisión documental de como la economía ha cambiado y a la forma en el que covid-19 ha afectado las cadenas de suministro.

\section{Aspectos teóricos}

Se está entrando en una etapa altamente recesiva, pues las proyecciones de crecimiento económico que se tenían, aunque modestas, se van a estancar o decrecer en este año 2020. Las potencias mundiales han tomado acciones de urgencia y atención a la crisis de salud pública provocada por el COVID-19 y tales decisiones conllevan impactos recesivos en esas economías que afectan al resto del mundo, especialmente a los países con los que mantenemos una relación comercial, turística y tecnológica (Segura, 2020).Según (Beker, 2020) La pandemia que azota a la humanidad está introduciendo cambios acelerados en múltiples aspectos de la realidad, incluyendo la económica. En muchos casos, está precipitando la entrada en vigor de cambios que ya se venían insinuando y que, en las nuevas condiciones de aislamiento social, han experimentado una virulenta aceleración. Sin ir más lejos, el proceso de conversión de procesos analógicos a digitales que hoy se vive en la realidad cotidiana (banca online, recetas médicas digitales, proliferación del teletrabajo, difusión del e-learning) ha venido para quedarse. Ya nada será como solía ser en la era A.C. (antes del Covid-19) en muchos aspectos de la realidad económicosocial.

Las dinámicas globales han cambiado drásticamente y las organizaciones de alguna manera no estaban preparadas para este cambio que trajo consigo la pandemia, porque se dieron en un lapso corto de tiempo, no obstante muchos fueron tomados por desprevenidos, probablemente nadie lo esperaba y los tiempos para dar respuesta no fueron suficientes para asimilar el cambio abrupto que traía consigo el covid-19, por lo que muchas organizaciones se tuvieron que dar a la tarea de cerrar sus negocios, otros se reinventaron saliendo de la figura tradicional por el uso de las nuevas tecnologías de la información como una forma de ser más competitivos, esto conlleva a pensar de que las empresas deben ser flexibles en una economía muy dinámica, cabe destacar que los procesos económicos tienen una dinámica muy particular a nivel mundial; y es que, se generan a partir de la interacción social y el intercambio entre individuos de la sociedad, puesto cualquiera alteración en las dinámicas de socialización y comunicación, también provoca un cambio, ya sea positivo o negativo en función de las operaciones comerciales y procesos económicos (Díaz \& Uparela, 2020).

Ahora bien, primero, hay un ambiente de enorme incertidumbre y temor, que inevitablemente frena el consumo de las personas y los hogares, y los proyectos empresariales de inversión. O sea, lo que cabe esperar es un proceso donde, al "abrirse" la economía, la gente retome a lo sumo de forma parcial algunos de sus viejos hábitos de consumo, pero manteniéndose cauta y contenida. En el caso de las empresas ese mismo efecto se daría, pero en grado incrementado, ya que se parte de un altísimo nivel de desocupación de la capacidad instalada. 
Difícilmente habrá alguna empresa que, bajo tales condiciones, quiera emprender nuevos proyectos de inversión. O sea, la reapertura tan solo dará un empujón parcial e insuficiente a la economía, y, por ello mismo, tan solo se recuperará una parte de los empleos perdidos. Por lo tanto, mucha gente que se quedó sin trabajo, no podrá recuperarlo, lo que, a su vez, mantendrá en pie poderosas fuerzas contractivas, que harán aún más limitada la recuperación de la demanda de consumo, y deprimirá aún más la disposición empresarial a generar nuevas inversiones. Los estímulos provenientes del exterior tampoco aportarán gran cosa. La profundidad de la recesión en países ricos, mantendrá deprimidas las exportaciones al menos por el resto de este año, pero

seguramente el efecto se prolongará al año venidero. El turismo, por su parte, durará mucho tiempo posiblemente años antes de retornar a niveles comparables a los de los tiempos pre-Covid. Hay demasiado miedo circulando en la atmósfera sicológica del mundo entero, para pensar otra cosa, ni siquiera si se adoptasen estrictas medidas sanitarias, y ni siquiera si se descubriese una vacuna eficaz, teniendo presente que aún si ésta estuviese disponible, su aplicación universal llevaría tiempo (Vargas, 2020).

Para la ejecución de trabajo se opta por hacer uso de una revisión bibliográfica a partir de trabajos recientes, se tomaron artículos, y fuentes reconocidas de información, a partir de la cuales se logró hacer un análisis sobre las nuevas dinámicas globales en el marco de la pandemia del covid-19.

\section{Resultados}

Figura 1

Ratio de crecimiento del comercio mundial de mercancías sobre crecimiento del producto interno bruto (PIB) mundial 1990-2020 (\% de cambio y ratio)

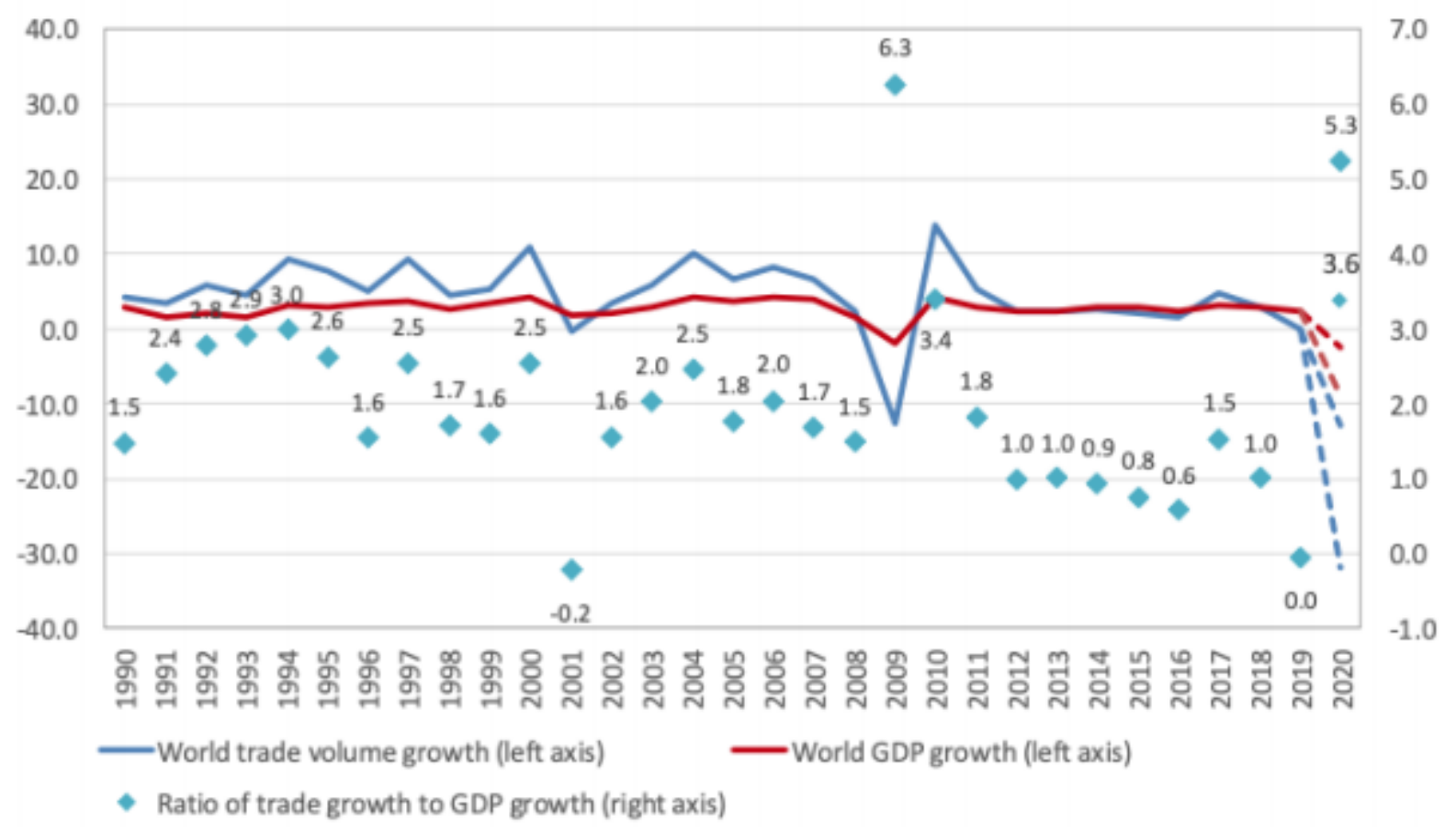

Fuente. Estimaciones de la Secretaria de la (OMC) para el comercio y el consenso sobre el PIB histórico. Las proyecciones sobre el PIB están basadas en escenarios simulados con el Modelo de Comercio Global de la OMC, (Tomado de Biurrun, 2020) 
En la figura 1. es evidente notar los fuertes altibajos en el comercio internacional, uno de ellos es el provocado por la crisis financiera y económica de 2008-2009, por otro lado, se evidencia la desaceleración ocurrida en el año 2019 y dos posibles escenarios que representan la caída del comercio y el PIB mundial provocada por el impacto de la COVID-19, en líneas discontinuas. También es destacable la rotura de la dinámica de la ratio crecimiento del comercio sobre crecimiento del PIB producida con la crisis de 2008-2009, pasando de una media de 2 a una media de 1 . Se antoja complicado predecir la evolución de esta ratio a partir del shock económico que produzca la pandemia. Los posibles escenarios que se plantean han sido llevados a cabo con base al modelo de comercio global de la OMC considerando, en el escenario más optimista, que las medidas de confinamiento se limiten a tres meses a nivel global y, a todo el año 2020, en el más pesimista. Parece por tanto más plausible el escenario optimista, dado que la mayoría de los países afectados se encuentran ya aliviando sus medidas de confinamiento. Cabe esperar, por tanto, una recuperación con forma de $\mathrm{V}$, el cual hace referencia a un receso brusco de la economía, pero la vuelta a la normalidad también es rápida. Es el escenario de recuperación más dinámico.

Sin embargo hablar de una reapertura puede parecer muy incierto y en cierta manera lograr que la economía alcance un respiro tomará un par de años, porque el miedo sigue en las personas, como se menciona en este artículo hay un ambiente de incertidumbre y es algo entendible, además de esos muchas personas han perdido su empleo, incluso si se logra una reapertura total, muchas cosas que se hacían antes del Covid-19 se retomaran, pero de forma parcial, con mucha prudencia, y con un común denominador, el miedo.

De igual manera la crisis sanitaria plantea un escenario complejo para la política económica, por la naturaleza sin precedentes del shock y porque sus repercusiones serán significativas. Se estima que el PIB sufrirá una severa contracción durante el primer semestre del año, seguida de un rebote que podría dejar la caída en el 3\% para el conjunto de 2020, siguiendo un impacto en forma de $U$, el cual hace referencia a aquellos indicadores económicos que tardan más tiempo en llegar a los niveles a los que se encontraban antes de la recesión. La mayoría de los expertos se inclinan por esta opción. Frente a vaticinios más alarmistas, este se sustenta en la evolución que ya se percibe en países donde el virus golpeó con anterioridad, como China y Corea del Sur. Así, en 2021 la economía española podría crecer un 2,8\%. Las medidas de emergencia adoptadas por el Gobierno y el Banco Central Europeo responden a esta situación, aunque habrá que seguir calibrando la intensidad de los estímulos en función de la duración de la crisis, con el objetivo de conservar el aparato productivo, mantener el empleo en empresas sostenibles y asegurar que el efecto rebote es el esperado (Torres \& Fernández, 2020). No obstante, y como lo menciona (cepal, 2020) el comercio mundial ya se estaba desacelerando antes del brote del coronavirus. En 2019, el volumen del comercio mundial de bienes cayó un 0,4\%, su primera disminución desde la crisis financiera mundial de 2008/2009. En gran medida, ello se debió a la progresiva acumulación de barreras comerciales desde principios de 2018 (principalmente entre los Estados Unidos y China) y su efecto dominó en las cadenas globales de valor altamente interconectadas.

En la mayoría de los países se ha utilizado como estrategia para controlar la expansión de la pandemia el aislamiento social, que se ha traducido en interrupciones en la producción de las empresas, sin importar el tamaño y giro; disminución en la demanda y por tanto en la producción. Mientras que en el mercado laboral, ha significado enviar a los más afortunados a casa a realizar teletrabajo; pero en economías como las de América Latina y particularmente México resulta aún más complicado al tener una base productiva basada en empresas de tamaño micro, pequeñas y medianas (99\%); y dónde el $56.7 \%$ del personal se ocupa en el sector informal, con un aporte del $22 \%$ al PIB; generando condiciones de desigualdad y vulnerabilidad para un amplio sector de la población en la medida que se dejen de demandar bienes y servicios, las empresas tenderán a despedir a sus empleados y los ingresos de empleados y autoempleados comenzarán a reducirse. Los datos hasta hoy reportados señalan que, por ejemplo, en el sector turístico del país ya se están registrando estos sucesos, cancelaciones y reprogramaciones de vacaciones; que se han traducido en despedidos (en Quintana Roo México, 
se prevé que el $40 \%$ de los empleados en el sector sean despedidos) (Girón, Barrón, \& Rojas, 2020). Son preocupantes los índices de desempleo en Latinoamérica, aún más cuando una gran cantidad de personas están bajo la informalidad, es notable la brecha que existe si se hace una comparación con otros países, en tal sentido muchos sectores se ven afectados debido a la poca demanda de bienes y servicios, las medidas de confinamiento han afectado a la economía.

Por otra parte la globalización ha traído consigo grandes retos para las organizaciones, por lo que han estado obligadas a reinventarse para lograr hacer frente a los nuevos desafíos, hoy en día existe lo que se conoce como mercado en línea como una nueva forma de hacer negocios, estas modelos han tomado mucha fuerza debido a que las personas pasan mucho más tiempo en su hogar cerca de un móvil o un computador, por ejemplo existen casos de éxitos como lo son Amazon, Alibaba, Aliexpress entre otros, estos se han apoderado de la ventas a través de internet, el uso de nuevas tecnologías ha hecho crecer de manera exponencial este tipo de negocios o emprendimientos, aun así este tipo de modelos de negocio no se construyen de la noche a la mañana, por el contrario tienen una trayectoria y han ganado la experiencia que los ha podido posicionar, ,no obstante la globalización es vulnerable dado el alto grado de interdependencia. Y también lo es el comercio internacional (y por ende el capitalismo también). Situaciones no previstas como el brote de COVID-19 requieren una respuesta

colectiva. Si estamos inmersos en problemas globales, entonces también tenemos que dar respuestas globales. Creo firmemente que, en las actuales circunstancias, el unilateralismo no sirve. La única salida rápida es el multilateralismo, la acción coordinada de todos los Estados. La responsabilidad de cada uno de los Estados contribuirá sin dudas, al bienestar global (Penci, 2020).

Cabe destacar que hoy día existen empresas que han basado su modelo de negocio en el uso de nuevas tecnologías (aplicaciones móviles, aplicaciones web, entre otros) tal es el caso de Amazon cuyos ingresos son muy altos y tal ha sido su éxito que han sido valoradas en miles de millones de dólares, y que han generado valor a través de plataformas multilaterales (MSP), las cuales facilitan las interacciones entre sus usuarios, algunas empresas tradicionales que no nacieron bajo el MSP tienen la dificultad de no darse cuenta de que de cierta manera puede migrar a este tipo de plataformas, en últimas el MSP permite obtener mayores resultados al lograr llegar a un mayor segmento de clientes, pero las dinámicas globales han cambiado desde la llegada de la pandemia.

Por otro lado, en América Latina y el Caribe se enfrenta la pandemia desde una posición más débil que la del resto del mundo. Antes de la pandemia, la CEPAL preveía que la región crecería un máximo del 1,3\% en 2020. Sin embargo, los efectos de la crisis han llevado a cambiar esa previsión y pronosticar una caída del PIB de al menos un 1,8\%. Sin embargo, no es de descartar que el desarrollo que la pandemia lleve a previsiones de contracciones de entre un $3 \%$ y un $4 \%$, o incluso más. El impacto económico final dependerá de las medidas que se tomen a nivel nacional, regional y mundial. Si bien es sabido resulta complejo comparar a los países latinoamericanos con países del primer mundo, existe una gran brecha la cual coloca en desventaja a muchos países latinoamericanos, los efectos de la crisis han golpeado la economía de manera sustancial indicando que el futuro depende de las decisiones que tome cada gobierno para hacer frente al covid-19.

Los efectos del COVID-19 agravan las ya débiles perspectivas del comercio exterior de América Latina y el Caribe. El acuerdo de "fase 1" entre los Estados Unidos y China celebrado en enero, en el que China se comprometió a aumentar sus importaciones de bienes y servicios de los Estados Unidos por lo menos en 77.000 millones de dólares en 2020, puede desplazar las exportaciones latinoamericanas y caribeñas a China en las mismas categorías de productos. Junto con la marcada caída de los precios del petróleo ya mencionada, el COVID-19 
llevará a una contracción del comercio internacional para la región en términos de valor y de volumen, a través de su impacto directo en la región y a través de sus socios comerciales (cepal, 2020).

A saber, uno de los sectores más golpeados por la pandemia ha sido el sector hotelero y turístico el surgimiento del virus covid-19 ha ocasionado una restricción para la realización de diferentes actividades que impliquen aglomeraciones, debido a que según lo expresado por la organización mundial de la salud "la enfermedad se propaga principalmente de persona a persona a través de las gotículas que salen despedidas de la nariz o la boca de una persona infectada al toser, estornudar o hablar", por tal razón; muchos países optaron por realizar cuarentenas obligatorias, además de cerrar fronteras con el objetivo de disminuir el contagio, lo anterior afecta directamente a la economía de los países; en el sector turístico por consiguiente se ve una afección. Pese a que según datos reportados por el Consejo Mundial del Turismo (WTTC) por sus siglas en inglés muestra que el sector de Viajes y Turismo experimentó un crecimiento de 3.5\% en 2019, superando el crecimiento de la economía global de $2.5 \%$ por noveno año consecutivo, adicionalmente expresa que este sector realizó una contribución de US \$ 8,9 billones al PIB mundial, lo que representa un 10,3\% del PIB mundial, cabe resaltar que este sector generó en ese año 330 millones de empleos, lo que representa 1 de cada 10 empleos en todo el mundo, demostrando así que este sector es un aliado para la creación de empleos a nivel mundial (wttc, 2020).

A nivel nacional, el sector del turismo para el año 2019 según los datos suministrados por el Ministerio de Comercio, Industria y Turismo, donde dio a conocer la satisfacción por cumplir las metas propuestas en este sector. Colombia experimentó un incremento en el turismo receptivo con una tendencia positiva en contraste con Suramérica. El país crece seis puntos porcentuales por encima de la región, mientras esta última decrece 3,5 $\%$, Colombia sube $2,7 \%$ (portafolio, 2020).

Lo anterior generó grandes expectativas de crecimiento en este sector tanto a nivel mundial como nacional para el año 2020. Expectativas que no se han podido cumplir debido al surgimiento del virus que ha impactado a la población mundial, Según la Organización Mundial de Turismo (OMT) de la ONU, el turismo en el 2020 se reducirá entre un 60 y un $80 \%$, poniendo en peligro entre 100 y 120 millones de empleos. Se trata del peor resultado desde 1950 y el fin de un crecimiento sostenido desde el 2009. "Desafíos considerables persisten, empezando por la desconocida duración de la pandemia y de las restricciones de viajes, en un contexto de recesión económica global", advierte el organismo (unwto, 2020).La cantidad de empleos ahora en riesgo en el sector global de viajes y turismo es de 75 millones, lo que genera una preocupación real y profunda para millones de familias en todo el mundo. Esta nueva cifra, escalofriante, también representa la demora colectiva de muchos gobiernos de todo el mundo para reaccionar lo suficientemente rápido como para ayudar a un sector que es la columna vertebral de la economía global, dijo en su momento Guevara Manzo (reportur, 2020).

\section{Conclusiones}

Para concluir y reconociendo el hecho de que el mundo ha cambiado mucho desde que se declaró la pandemia, los gobiernos se han visto en la obligación de recurrir a las medidas de confinamiento como una opción para contrarrestar la propagación del covid-19, no obstante, la economía mundial se ha visto afectada porque las personas han dejado de consumir productos y servicios de ciertos sectores. Por otra parte hay que recalcar que algunas empresas aún se encuentran rezagadas en modelos tradicionales que de cierta manera no tienden a ser competentes con el mercado internacional, lo que podría funcionarles desde su locación, posiblemente no serviría para ser más competitivos en un campo más internacional o global, estas se han visto en la obligación de reinventarse para poder hacer frente a los nuevos desafíos que ha traído consigo la pandemia haciendo uso de las nuevas tecnologías; de igual manera es importante que las organizaciones se reinventen actualizando sus competencias y sus capacidades para poder competir en el mercado cada vez más cambiante y evolutivo, si bien es cierto que el futuro guarda un poco de incertidumbre, existe la esperanza de que unidos en un mundo 
globalizado las cosas mejoren, la economía mejore, y de cierta manera se recupere con cautela lo que antes del covid-19 se hacía con normalidad, la humanidad ha atravesado por diferentes pandemias y está claro que quien mejor se adapte a las circunstancias tendrá una ventaja por sobre los demás, al saber cómo hacer frente a los nuevos desafíos que trae el mundo.

\section{Referencias}

Beker, v. (2020). El impacto del covid-19 en la economía global. Universidad de belgrano-centro de estudios de la nueva economía, 9.

Biurrun, a. (2020). Evolución histórica de las cadenas globales de valor. 11.

Cepal. (2020). América latina y caribe ante la pandemia del covid-19 efectos económicos y sociales. 15.

Díaz, i., \& uparela, r. (2020). Covid-19 y sus posibles efectos en los negocios internacionales. Colombia: universidad de córdoba.

Girón, m., barrón, k., \& rojas, a. (2020). The covid-19 pandemic: impact in health and economy. 1revista bio ciencias, 6.

Penci, a. (2020). Covid-19, estados y globalización:¿ capitalismo internacional y democracias en apuros?. 6.

Portafolio. (2020). Obtenido de https://www.portafolio.co/economia/el-turismo-del-pais-crecio-seis-puntosporcentuales-en-2019-538422

Reportur. (25 de 03 de 2020). Obtenido de https://www.reportur.com/colombia/2020/03/25/wttc-eleva-cifraperdida-empleos-turismo-

mundo/\#: :text=\%e2\%80\%9cla\%20cantidad\%20de\%20empleos\%20ahora,familias\%20en\%20todo\%20el\%

20mundo.\&text=(wttc\%3a\%20turismo\%20pierde\%20un\%20mill\%c3\%b3n,empleos\%20diarios\%20e

Segura, o. (2020). Economía y covid-19.

Torres, r., \& fernández, f. (2020). La política económica española y el covid-19. Funcas, cuadernos de información económica, 7.

Unwto. (20 de 05 de 2020). Unwto.prg. Obtenido de https://www.unwto.org/es/news/omt-presenta-susdirectrices-globales-para-reabrir-el-turismo

Vargas, I. (2020). Covid-19 y “apertura” de la economía: no nos hagamos ilusiones. Revista rupturas, 4.

Wttc. (2020). Wttc. Obtenido de https://wttc.org/research/economic-impact

Esta obra está bajo una Licencia Creative Commons

Attribución-NoCommercial 4.0 International

(cc) EY-NC 